\title{
TOPICAL APPLICATION OF EUGENIA CARYOPHYLLUS OIL AGAINST RINGWORM INFECTION OF HUMAN BEINGS
}

\author{
NEETU JAIN ${ }^{1 *}$, MEENAKSHI SHARMA ${ }^{2}$ \\ ${ }^{1}$ SS Jain Subodh PG (Autonomous) College, ${ }^{2}$ Laboratory of Medical Mycology and Plant Pathology, Department of Botany, University of \\ Rajasthan, Jaipur, Rajasthan, India. Email: neetugodika@yahoo.co.in
}

Received: 15 January 2019, Revised and Accepted: 15 May 2019

\begin{abstract}
Objective: At least one million people are suffering from dermatophytosis in India. These mycoses although normally not lethal are unpleasant, frequent disease recurrence, and resistant dermatophytic strains cause considerable economic losses. During the antifungal evaluation of essential oil of Eugenia caryophyllus, all concentrations were found to be an excellent inhibitor against selected fungi as compared to standard antifungal drugs griseofulvin, ketoconazole, and itraconazole. The present work deals with the preparation of an ointment from E. caryophyllus oil for the treatment of ringworm infection in human beings.
\end{abstract}

Materials and Methods: Due to these potent fungicidal properties, an ointment of E. caryophyllus was prepared and topically applied on tinea patients attending the outpatient Department of Skin, Venereology, and Leprology, SMS Hospital, Jaipur. Patients were diagnosed as tinea corporis, tinea capitis, tinea manuum, and tinea barbae. The medication was done twice a day for 3 weeks as advised by the skin specialist.

Results: All patients showed positive potassium hydroxide $(\mathrm{KOH})$ results at the beginning of the trial. After the $2^{\text {nd }}$ week of treatment, every patient was $\mathrm{KOH}$ negative and remained negative when re-examined after one month of treatment. All patients were completely cured within 3 weeks of the treatment.

Conclusions: Ointment showed excellent results, found cheaper substitutes to cure the disease without any adverse side effect. The present study offers a high possibility of complete cure of tinea infection and suggesting its uses as raw material by pharmaceutical industries for the development of antidermatophytic drug in prevailing conditions where dermatophytes are becoming resistant against popular antifungals.

Keywords: Dermatophytosis, Tinea corporis, Tinea barbae, Tinea capitis, Tinea manuum, Essential oil.

(C) 2019 The Authors. Published by Innovare Academic Sciences Pvt Ltd. This is an open access article under the CC BY license (http: //creativecommons. org/licenses/by/4. 0/) DOI: http://dx.doi.org/10.22159/ajpcr.2019.v12i7.32068

\section{INTRODUCTION}

Dermatophytosis poses a serious concern to the sociologically backward and economically poor population of India. In dermatophytic infection of the skin, the fungus remains confined to the stratum corneum while pathogenic changes are produced in the deeper layer of the epidermis and dermis as per medical observation. These fungi produced a ringshaped lesion of infected skin. Clinical surveys [1-4] carried out in India have shown ringworm as one of the most common dermatomycoses caused by the species of Epidermophyton, Microsporum, and Trichophyton. The disease is predominant in tropical and subtropical countries due to their, prevailing moisture and temperature regimes and pose a therapeutic problem $[5,6]$. Despite the availability of new systemic antifungal therapies, dermatophytic infections are difficult to eradicate completely, with recurrence reported in up to $25 \%-40 \%$ of cases [7]. Many antifungal synthetic drugs, namely terbinafine imidazoles and butenafine are found effective against dermatophytosis [8]. However, disease recurrence, resistant dermatophytic strains, and adverse effects are some drawbacks associated with popular antifungals.

In recent years, there has been a gradual revival of interest in the use of medicinal plants in developed as well as in developing countries, because herbal medicines have been reported to be safe and without any adverse side effect thus, a search for new drugs with better and cheaper substitutes from plant resources are a natural choice [9-14].

These finding promoted us to explore other plant products which could be exploited as effective antifungals. In our previous work, we explored Trachyspermum ammi oil against ringworm infection of human beings and all patients were cured successively without any adverse effect [15].
Recently, we have carried out the detailed antifungal study of the essential oil obtained from the flowering bud of E. caryophyllus in vitro as well as in clinical trials against ringworm infection in human beings. Eugenia or clove oil has been used as dental care product from the ancient time, but no work has been reported as dermal care product till now especially for ringworm treatment.

\section{MATERIALS AND METHODS}

Oil extraction

Clove flowering buds purchased from the local market of Jaipur city in April 2012 were identified by Prof. P. C. Jain, Department of Botany, University of Rajasthan, Jaipur. The semi-crushed buds were hydrodistilled in a Clevenger's apparatus for $4 \mathrm{~h}$. Moisture free oil was then stored in amber colored bottles and kept in the refrigerator. The oil yield was $4.1 \%(\mathrm{v} / \mathrm{w})$.

\section{Microorganism for in vitro studies}

Clove oil was evaluated for their antifungal properties against selected pathogens. Trichophyton rubrum and Trichophyton simii were isolated from infected skin scrapings of tinea patients from SMS Hospital, Jaipur, while Chrysosporium tropicum and Chrysanthemum indicum were isolated from soil samples through To. Ka. Va. hair baiting technique of Vanbreuseghem [16]. These fungi were maintained on Sabouraud's dextrose agar medium.

\section{Screening of oil}

The filter paper disc diffusion assay by Wannisorn et al. [17] was used with slightly modification for screening the essential oils against 
dermatophytes. Standard size Whatman no. 1 filter paper discs $6.0 \mathrm{~mm}$ in diameter, sterilized by dry heat at $140^{\circ} \mathrm{C}$ in an oven for $1 \mathrm{~h}$ was used to determine antifungal activity. $20 \mathrm{ml}$ sterilized Sabouraud's dextrose agar medium was taken in each autoclaved Petri dish and allowed to solidify. The fungal spore suspension was prepared in sterilized $0.85 \%$ saline water by transferring a loopful of 15 day-old culture. $1 \mathrm{ml}$ of spore suspension of approximately $0.5-5 \times 10^{4}(\mathrm{cfu} / \mathrm{ml})$ was spread over the respective agar medium plates. Sterilized filter paper was soaked in neat undiluted oil. An oil saturated disc was placed on an agar plate containing fungal spore suspension. Ketoconazole was used as a standard drug. These plates were incubated. Five replicates were kept in each case, and the average values were determined, and inhibition zone (IZ) was observed. The antifungal activity was determined by measuring the IZ around the disc. The activity of the oil was measured by the following formula.

Activity Index (AI) $=\frac{\text { Inhibition Zone (IZ) of samples }}{\text { Inhibition Zone (IZ) of standard }}$

Minimum inhibitory concentration (MIC) through semisolid agar antifungal susceptibility method:

Semisolid agar antifungal susceptibility testing method of Provine and Hadley [18] for endpoint determination (MIC) was carried out in BHIA (HiMedia). BHIA was prepared according to manufacturer's instruction.

\section{Inoculum preparation}

Sterile swab dipped into sterile tween 80 was used to pick the pure colony of yeast. This was then suspended in 3-4 $\mathrm{ml}$ of sterile normal saline and vortexed. The turbidity of the homogenous suspension was adjusted to $\sim 0.5 \mathrm{McFarland}$ standard. Similarly, inoculum was prepared for filamentous fungi $\left(3-7\right.$ days old slant at $37^{\circ} \mathrm{C}$ on potato dextrose agar). By swabbing the pure colony (mixture of conidia and hyphal fragments) was suspended in 3-7 ml of sterile saline. The mixture was vortexed and heavy particles were allowed to settle. The homogenous suspension was adjusted to $0.5 \mathrm{McF}$ arland standard.

\section{Inoculation of drug-containing tubes}

The semisolid agar tubes containing known concentrations of test oils as well as oil-free controls, prepared in duplicate, were inoculated with one loopful (HiMedia Flexiloop 4) of 0.5 McFarland adjusted culture by inserting the loop deep within the semisolid agar. The tubes were incubated at $37^{\circ} \mathrm{C}$ for $48 \mathrm{~h}(96 \mathrm{~h}$ for dermatophytes). A loopful of the inoculum suspension was streaked onto Sabouraud dextrose agar to check for purity and viability.

\section{Endpoint determination}

Endpoint determination was done according to the NCCLS/CLSI guidelines, M27-A, and M38-A. Growth was compared to that of oilfree control and scored by visual inspection as follows: +4 : growth same as control; +3 : slight decrease in growth; +2 : significant reduction in growth reduction $80 \%$ in yeast and $50 \%$ in filamentous; +1 slight growth or few visible hyphal fragments; and 0: no growth.

\section{Statistical analysis}

Statistical analysis was carried by one-way ANOVA following multiple comparison tests Turkeys method. Data are expressed as the mean and standard error of the mean.

\section{Ointment preparation and application}

About 1\% concentration of E. caryophyllus was (clove oil) prepared in petroleum jelly and labeled it as ointment EC.

A comparative efficacy of E. caryophyllus with different antimycotic drugs such as griseofulvin, itraconazole, and ketoconazole showed that all concentrations of E. caryophyllus were found to more effective than standard drugs. In our previous work Jain and Sharma, 2003, we also used $1 \%$ and $2 \%$ concentration of T. ammi oil against dermatophytes causing ringworm infection of human being and cured all patient successively. Before applying this ointment of tinea patients patch test of Roxburgh and Borrie [19] was followed to find out whether these ointments have any irritant activity or not.

\section{Clinical application}

For in vivo investigation, patients (male and female) of different age groups (infant to 50 years) were selected. All patients were voluntary. A total of 35 patients were selected for study to see the clinical response of ointment. This was applied topically on patients to control the fungal infection. The medication was done twice a day for 3 weeks as advised by the skin specialist. The patients were not allowed to take any other systemic or topical therapy during the course of the present study.

Patients were diagnosed for different clinical types such as tinea corporis, tinea capitis, tinea manuum, and tinea barbae based on site and type of infection. The diagnosis was further confirmed by microscopic examination of scrapings (from infected area) treated with $10 \% \mathrm{KOH}$. Only $\mathrm{KOH}$ positive cases were enrolled for the study. Patients were examined just before the start of therapy and at the end of each week of the treatment, up to their complete cure. At each visit of the patient, the same reference lesion was scraped for fungal culture to identify the organism and for demonstration of the presence of hyphae by microscopic examination of the scraping which was covered with $10 \% \mathrm{KOH}$ preparation. Signs and symptoms of inflammation as erythema, scaling, itching, maceration, vesiculation, and pustulation were recorded as mild, moderate, severe, or absent. The fungal culture was identified by standard protocol.

Additional information of patients regarding their profession, living conditions, along with clinical diagnosis-site of infection, primary or secondary infection, sex, age were also recorded. Usually, patients with secondary infection were avoided for the study. Although the cutaneous fungal disease manifested itself in several body areas and all the affected areas were treated, only one was selected and designated

Table 1: Comparison of efficacy of Eugenia caryophyllus oil with commercial antifungal drugs

\begin{tabular}{|c|c|c|c|c|c|c|c|c|c|c|c|c|c|c|}
\hline \multirow{4}{*}{$\begin{array}{l}\text { Concentrations } \\
\text { of oil (\%) }\end{array}$} & \multicolumn{14}{|c|}{ Test fungi } \\
\hline & \multicolumn{4}{|c|}{ Trichophyton rubrum } & \multicolumn{4}{|c|}{ Trichophyton simii } & \multicolumn{2}{|c|}{ Chrysosporium indicum } & \multicolumn{4}{|c|}{ Chrysosporium tropicum } \\
\hline & \multirow[t]{2}{*}{ IZ } & \multicolumn{3}{|l|}{ AI } & \multirow[t]{2}{*}{ IZ } & \multicolumn{3}{|l|}{ AI } & \multirow[t]{2}{*}{ IZ } & \multirow{2}{*}{$\frac{\mathrm{AI}}{\mathrm{TC} / \mathrm{K}}$} & \multirow[t]{2}{*}{$I Z$} & \multicolumn{3}{|l|}{ AI } \\
\hline & & TC/G & TC/I & $\mathrm{TC} / \mathrm{K}$ & & TC/G & $\mathrm{TC} / \mathrm{I}$ & TC/K & & & & TC/G & TC/I & $\mathrm{TC} / \mathrm{K}$ \\
\hline 25 & 25 & 0.893 & 1.190 & 0.490 & 18 & 0.750 & 0.9 & 0.486 & 30 & 1.765 & 28 & 0.8 & 1.647 & 0.718 \\
\hline 50 & 47 & 1.679 & 2.238 & 0.921 & 36.33 & 1.514 & 1.816 & 0.982 & 42 & 2.470 & 36 & 1.028 & 2.118 & 0.923 \\
\hline 75 & 75 & 2.679 & 3.571 & 1.470 & 55 & 2.292 & 2.75 & 1.486 & 50 & 2.941 & 52 & 1.495 & 3.078 & 1.342 \\
\hline 100 & 95 & 3.393 & 4.524 & 1.863 & 71 & 2.958 & 3.55 & 1.919 & 57 & 3.353 & 58 & 1.648 & 3.392 & 1.479 \\
\hline
\end{tabular}

IZ: Inhibition zone including $6 \mathrm{~mm}$ diameter of filter paper disc, AI: Activity index, TC: Test compound. Inhibition zones of standard griseofulvin (G) against Trichophyton rubrum $=28 \mathrm{~mm}$; Trichophyton simii $=24 \mathrm{~mm}$; Chrysosporium tropicum $=35 \mathrm{~mm}$. Inhibition zones of standard itraconazole (I) against Trichophyton rubrum=21 mm; Trichophyton simii $=20 \mathrm{~mm}$; Chrysosporium tropicum $=17 \mathrm{~mm}$. Inhibition zones of standard ketoconazole (K) against Trichophyton rubrum=51 mm; Trichophyton simii $=37 \mathrm{~mm}$; Chrysosporium tropicum=39 mm; Chrysosporium indicum $=17 \mathrm{~mm}$ 
as the reference lesion. At each visit of the patients, overall clinical improvement was reported as none, partial, significant, or completely clear by comparing the state of their infection with the state at the time of their initial visit. Adverse systemic or local reactions were noted (at each visit) and recorded as mild, moderate, or severe.

\section{RESULTS}

E. caryophyllus is very well studied nowadays. Lots of works have been done on the chemical composition of eugenia oil [20-24]. Eugenol is a major constituent of eugenia oil ranging from $82 \%$ to $90 \%$ according to collection time and cultivation place. Other components are trans- $\beta$ caryophyllene, eugenyl acetate, $\alpha$-humulene, chavicol, $\beta$-caryophyllene oxide, $\alpha$-cubebene, $\alpha$-copaene, and $\delta$-cadinene.

\section{In vitro antidermatophytic activity}

Four concentrations of Eugenia oil were prepared and applied against selected dermatophytes. Data were compared with the most commonly used standard allopathic drugs such as ketoconazole, itraconazole, and griseofulvin (Table 1). In the case of C. indicum, all four concentrations of clove oil exhibited more prominent inhibitory effects than ketoconazole. Griseofulvin and itraconazole were devoid of any antifungal effect against this fungus. In the case of T. rubrum, 100\%, 75\%, and 50\% clove oil

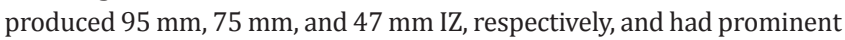
efficacy in comparison to griseofulvin ( $\mathrm{IZ}=28 \mathrm{~mm}$ ) and itraconazole $(\mathrm{IZ}=21 \mathrm{~mm})$. A comparative efficacy of this oil with ketoconazole against T. rubrum showed that $100 \%$ and $75 \%$ oil had excellent inhibitory properties (Activity index $[\mathrm{AI}]=1.863$ and 1.470 , respectively) while $50 \%$ concentration showed slightly less effect $(\mathrm{AI}=0.921)$. The same results were also seen in T. simii and C. tropicum. 100\%, 75\%, and 50\% oil showed a more prominent effect than griseofulvin and itraconazole. $25 \%$ concentration also showed stronger effect than itraconazole in the case of $C$. tropicum (AI = 1.647) and was slightly comparable with itraconazole in the case of $T$. simii $(\mathrm{AI}=0.9)$. Maximum zone of inhibition $95 \mathrm{~mm}$ was recorded against T. rubrum in the presence of pure oil (Fig. 1).

\section{MIC of clove oil}

In present investigation, MIC of clove oil against seven selected fungi, namely Candida albicans, T. rubrum, T. verrucosum, M. gypseum, $M$. canis, M. fulvum, and $F$. verticilloides was carried by SAAS method (Table 2). Clove oil showed excellent antidermatophytic activity against all test fungi. MIC of clove oil against T. rubrum was found to be $0.05 \pm$ $0.000 \mu \mathrm{l} / \mathrm{ml}$ followed by $0.1 \mu / \mathrm{ml}$ for C. albicans, M. gypseum, M. canis, T. verrucosum, and M. fulvum. MIC for $F$. verticillioides was found to be $0.2 \pm 0.002 \mu \mathrm{l} / \mathrm{ml}$

\section{In vivo experiment}

Data incorporated in Table 3 show that all the 35 patients of tinea infection recovered completely with the timely application of these ointments (Figs. 2 and 3)

\section{Tinea corporis}

A complete treatment period of tinea corporis differs (4-6 weeks) with the different allopathic drug. Out of 15 patients treated with ointment EC, three showed complete relief within 1 week, nine patients were completely cured in the $2^{\text {nd }}$ week, and the remaining showed complete

Table 2: Minimal inhibitory concentration $(\mu \mathrm{l} / \mathrm{ml})$ of essential oils against selected dermatophytes

\begin{tabular}{ll}
\hline Fungal species & MIC \\
\hline Candida albicans & $0.1 \pm 0.000$ \\
Microsporum gypseum & $0.1 \pm 0.033$ \\
Microsporum canis & $0.1 \pm 0.002$ \\
Trichophyton rubrum & $0.05 \pm 0.000$ \\
Trichophyton verrucosum & $0.1 \pm 0.000$ \\
Microsporum fulvum & $0.1 \pm 0.033$ \\
Fusarium verticillioides & $0.2 \pm 0.002$ \\
\hline
\end{tabular}

cure during the $3^{\text {rd }}$ week of treatment. Trichophyton rubrum and T. simii were the main causative agents of tinea corporis.
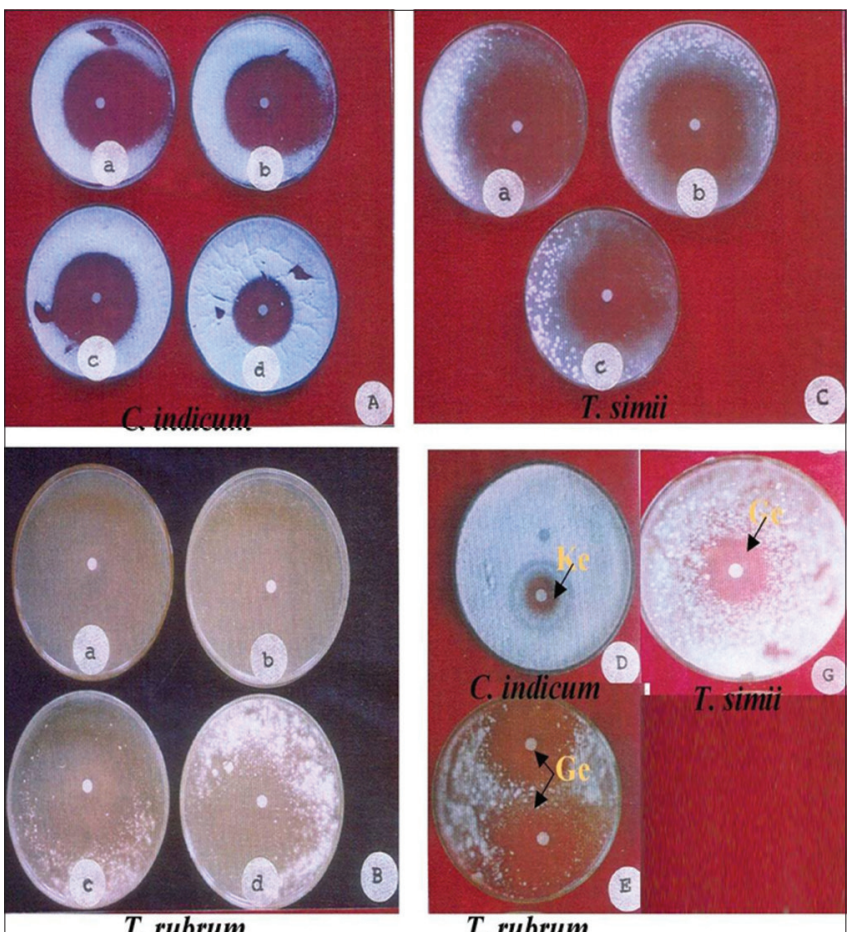

T. rubrum

T. rubrum

Fig. 1: Efficacy of Eugenia caryophyllus

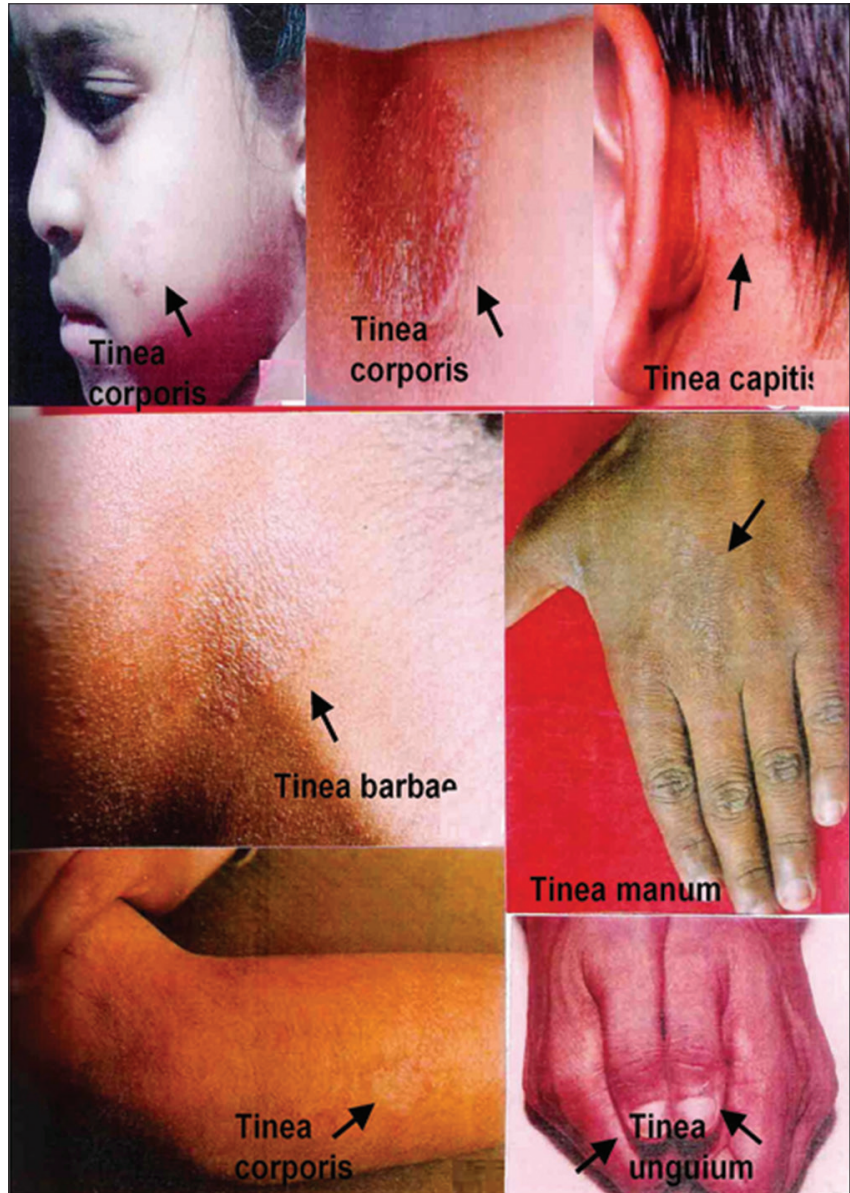

Fig. 2: Showing different clinical types of tinea infection 


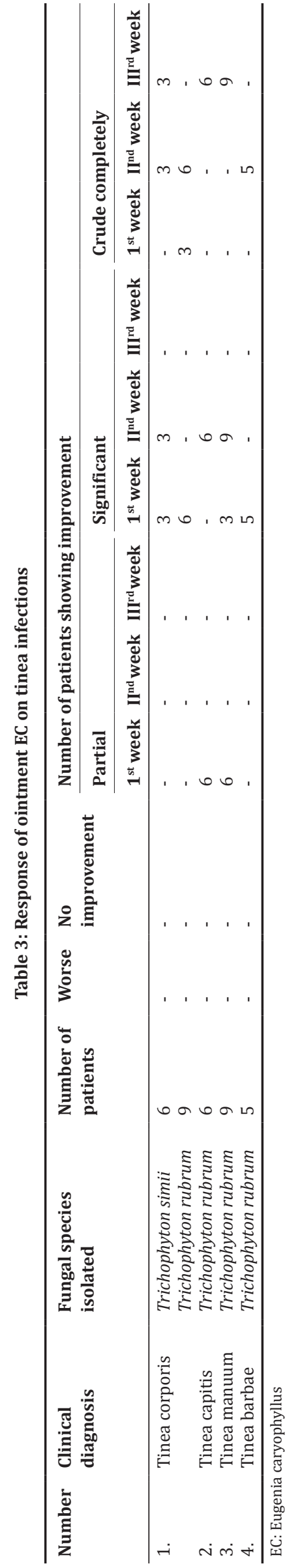

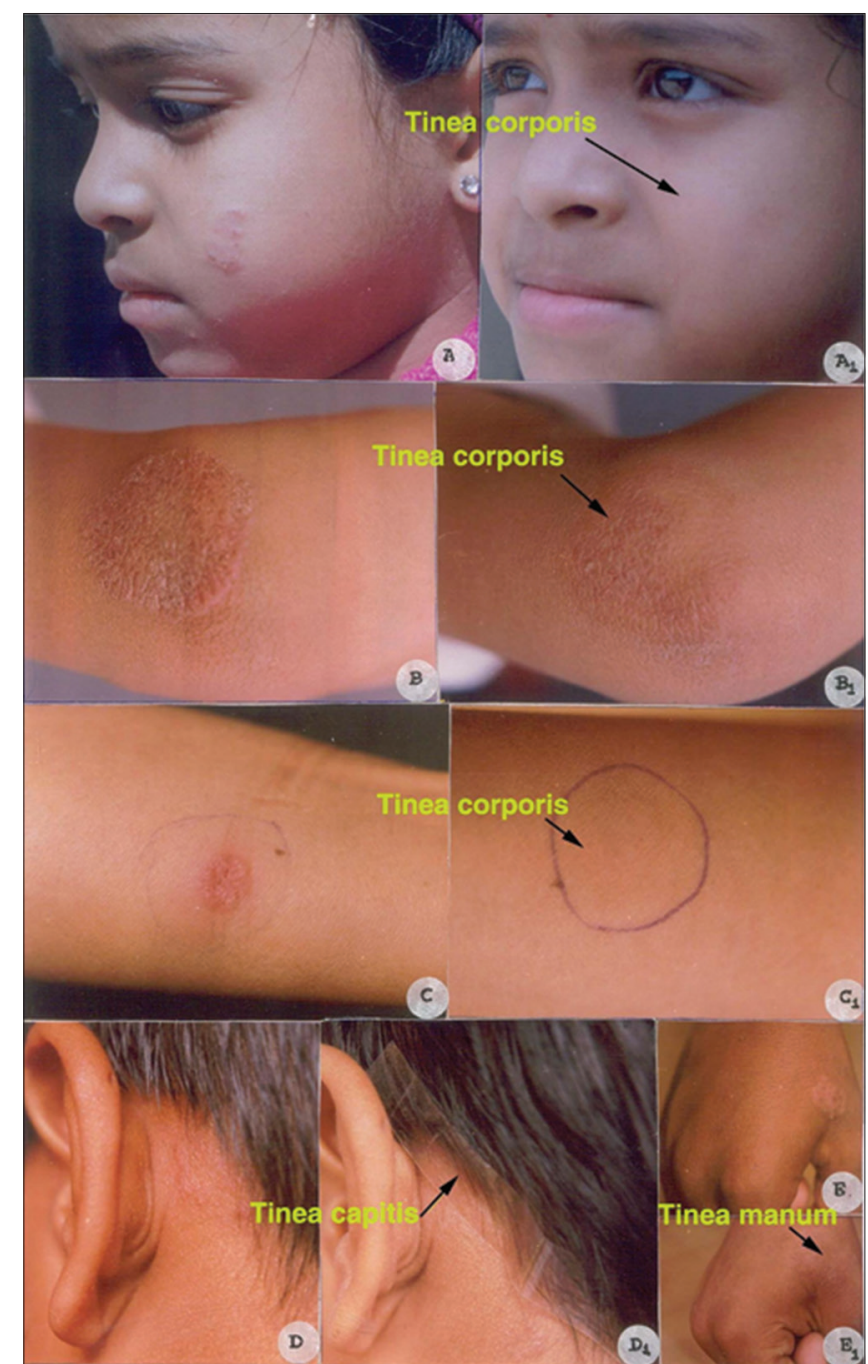

Fig. 3: Treatment of different clinical types with ointment EC

\section{Tinea capitis}

A total of six patients of tinea capitis were treated with ointment EC. All patients showed significant improvement in the $2^{\text {nd }}$ week of treatment and cured completely within 3 weeks without any adverse side effect.

\section{Tinea manuum}

A complete treatment period of tinea manuum is 6-8 weeks with different drugs. In present investigation out of nine patients of tinea manuum, three patients showed significant improvement in $1^{\text {st }}$ week, and rest six in $2^{\text {nd }}$ week. All patients completely cured within 3 weeks.

\section{Tinea barbae}

Five patients of tinea barbae suffering from Trichophyton rubrum showed significant improvement in $1^{\text {st }}$ week of treatment and completely cured in the $2^{\text {nd }}$ week of treatment.

During the present study, all patients of ringworm infection were completely cured in 12-18 days of treatment without any adverse side effect. Ointment, when tested for its irritation activity on experimental animals, did not show any irritation effect. The same result also observed during the patch test method on a human being.

\section{DISCUSSION}

During present investigation, E. caryophyllus oil exhibited excellent antidermatophytic activity as compared to standard allopathic drugs 
such as griseofulvin, ketoconazole, and itraconazole. Antifungal and antidermatophytic properties of clove were also reported [25,26]. Therefore, $1 \%$ concentration of oil was used to prepared ointment EC.

A complete treatment time of the different clinical type of tinea infection differs from 4 to 10 weeks with different allopathic drugs. During treatment, all patients of ringworm infection were completely cured in 12-18 days of treatment without any adverse side effects. Out of 15 patients of tinea corporis, three cured completely within a week, nine after the $2^{\text {nd }}$ week of treatment and the remaining were cured after $3^{\text {rd }}$ week of treatment. Six patients of tinea capitis and nine of Tinea manuum were completely cured in $3^{\text {rd }}$ week of treatment. Likewise, all patients of tinea barbae were cured in the $2^{\text {nd }}$ week of treatment. Ointment, when tested for its irritation activity on experimental animal, did not show any irritation effect. The same result also observed during the patch test method on human being.

In our previous work [15], we explored T. ammi essential oil against dermatophytes and found excellent results. During the comparative analysis of both oils, Eugenia oil exhibited more prominent antidermatophytic activity (laboratorically and clinically) as compared to T. ammi oil. Shahi et al. [27] also used 1\% concentration of Eucalyptus citriodora oil against dermatophytic infection of a human being. At the end of treatment, $55.5 \%$ of patients recovered completely and $45.5 \%$ of them showed significant improvement. Shahi et al. [28] used $1.0 \mu \mathrm{l} / \mathrm{ml}$ concentration of Eucalyptus pauciflora against selected human pathogenic fungi and prepared an ointment $(1 \% \mathrm{v} / \mathrm{v})$ for ringworm infections of human beings. At the end, $60 \%$ of patients recovered completely and $40 \%$ showed significant improvement from the disease.

\section{CONCLUSION}

The oil of E. caryophyllus due to its strong antifungal activity inhibiting heavy doses of inoculum having fungicidal properties and with no irritation on human skin can be used successfully in the form of broad-spectrum antimycotic drug for the control of superficial fungal infection in human beings. E. caryophyllus also exhibited stronger antidermatophytic compound as compared to all synthetic antifungal drug prescribed by doctors during the course of treatment. These have been found to be better and effective substitutes for curing the disease without any adverse side effect. They are easy to apply and respond much faster than synthetic allopathic preparations. Isolation and identification of active principles of E. caryophyllus at different temperature interval for antidermatophytic activity are in progress.

\section{ACKNOWLEDGMENT}

The authors are thankful to Dr. Shayam Mittal, University Dispensary, University of Rajasthan, Jaipur, for technical support during the handling of patients. We are also thankful to the Department of Science of Technology New Delhi, for financial assistant during research work.

\section{AUTHORS' CONTRIBUTIONS}

Dr. Neetu Jain carried out all the experiments while Dr. Meenakshi Sharma designed the experiments and help in the preparation of the manuscript.

\section{CONFLICTS OF INTEREST}

No conflicts of interest.

\section{REFERENCES}

1. Gupta BK, Kumar S, Kumar RA, Khurana S. Mycological aspects of dermatomycosis in Ludhiana. Indian J Pathol Microbiol 1993;36:233-7.

2. Patwardhan N, Dave R. Dermatomycosis in and around Aurangabad. Indian J Pathol Microbiol 1999;42:455-62.
3. Jain N, Sharma M, Sexana VN. Clinico-mycological profile of dermatophytosis in Jaipur, Rajasthan. Ind J Derma Venero Lepro 2008;74:274-5.

4. Sharma M, Sharma R. Profile of dermatophytic and other fungal infections in jaipur. Indian J Microbiol 2012;52:270-4.

5. Lohoué Petmy J, Lando AJ, Kaptue L, Tchinda V, Folefack M. Superficial mycoses and HIV infection in yaounde. J Eur Acad Dermatol Venereol 2004;18:301-4.

6. Maraki S, Tselentis Y. Dermatophytoses in crete, Greece, between 1992 and 1996. Mycoses 1998;41:175-8

7. Hay RJ. The future of onychomycosis therapy may involve a combination of approaches. Br J Dermatol 2001;145 Suppl 60:3-8.

8. Watanabe S. Present state and future direction of topical antifungals. Nihon Ishinkin Gakkai Zasshi 1999;40:151-5.

9. Lozoya X, Navarro V, García M, Zurita M. Solanum chrysotrichum (Schldl.) a plant used in Mexico for the treatment of skin mycosis. J Ethnopharmacol 1992;36:127-32.

10. Damodaran S, Venkataraman S. A study on the therapeutic efficacy of Cassia alata, Linn. Leaf extract against pityriasis versicolor. J Ethnopharmacol 1994;42:19-23.

11. Radika SM, Michael A. In vitro antifungal activity of leaves extracts of Azadirachta indica. Int J Pharm Pharm Sci 2013;5:723-5.

12. Jain N, Sharma M. Screening of Thymus vulgaris essential oil against fungi causing dermatophytosis in human beings. Int J Pharm Pharm Sci 2017:9:236-9.

13. Jain N, Sharma M, Kumar P. Regulatory effect of some plant extracts on the growth of dermatophytic fungi. Indian J Microbiol 2004;14:56-61.

14. Jain N, Sharma M, Joshi S, Kaushik U. Toxicological aspect, chemical composition and antidermatophytic activity of essential oil of Trachyspermum ammi and their fractions. Indian J Pharm Sci 2018;80:136-42.

15. Jain N, Sharma M. Broad spectrum antimycotic drug for the treatment of ring worm infection in human beings. Curr Sci 2003;85:30-4.

16. Vanbreuseghem R. Biological technique for isolating dermatophytes from soil. Ann Soc Belg Med Trop (1920) 1952;32:173-8

17. Wannisorn B, Jariksam S, Soontorntanasart T. Antifungal activity of lemon grass and lemon grass oil cream. Phytother Res 1996;10:551-4.

18. Provine H, Hadley S. Preliminary evaluation of a semisolid agar antifungal susceptibility test for yeasts and molds. J Clin Microbiol 2000;38:537-41.

19. Roxburgh AC, Borrie P. The English language Book Soceity. London: H.K. Kewis and Co. Ktd.; 1973.

20. Raina VK, Srivastava SK, Aggarwal KK, Syamsunder KV, Kumar S. Essential oil composition of Syzygium aromaticum leaf from little Andaman, India. Flavour Fragr J 2001;16:334-6.

21. Srivastava SK, Syamsunder KV. Bud and leaf essential oil composition of Syzygium aromaticum from India and Madagascar. Flavour Fragr J 2005;20:51-3

22. Alma H, Murat E, Nitz S, Kollmannsberger H. Chemical composition and content of essential oil from the bud of cultivated Turkish clove (Syzygium aromaticum). Bio Resour 2007;2:265-9.

23. Mahmoud IN, Ahmed HG, Ahmed HE, Farrag AR, Shen H, Huq E, et al. Chemical constituents of clove (Syzygium aromaticum, Fam. Myrtaceae) and their antioxidant activity. Rev Latinoam Quimica 2007:35:47-57.

24. Bankar R, Kumar A, Puri S. Phytochemical constituent of Syzygium aromaticum. Int J Curr Res 2011;3:215-7.

25. Jatisatienr C, Tragoolpua K, Pank F. Effect of the Extract from Eight sps. of Medicinal Plants on Growth of Selected Plant Pathogenic Molds and Dermatophytes. Vol. 2. Proceedings, International Symposium, Breeding Research on Medicinal and Aromatic Plants. Quedlinburg, Germany, June 30-july 4, 1996. Beitrage Zur Zuctungsforchung Bundesanstalt fur Zuchtungsforchung an Kulturpflanzen; 1996. p. 414-7.

26. Bouddine L, Louaste B, Achahbar S, Chami N, Chami F, Remmal A. Comparative study of the antifungal activity of some essential oils and their major phenolic components against Aspergillus niger using three different methods. Afr J Biotechnol 2012;11:14083-7.

27. Shahi SK, Shukla AC, Bajaj AK, Banerjee U, Rimek D, Midgely G, et al. Broad spectrum herbal therapy against superficial fungal infections. Skin Pharmacol Appl Skin Physiol 2000;13:60-4

28. Shahi KS, Shukla AC, Bajaj AK, Medgely G, Dikshit A. Broad spectrum antimycotic drug for the control of fungal infection in human beings. Curr Sci 1999;76:836-8. 